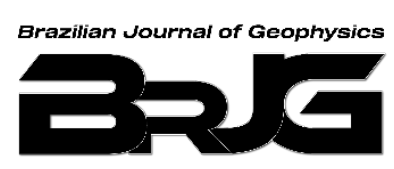

\title{
WELL-SEISMIC INTEGRATION TO PORE PRESSURE PREDICTION USING MULTIVARIATE GEOSTATISTICS: A CASE STUDY IN A BRAZILIAN EQUATORIAL MARGIN BASIN
}

\author{
Flávia Braz Ponte ${ }^{1}$, Francisco Fábio de Araújo Ponte ${ }^{2}$, Adalberto Silva ${ }^{2}$ and Alberto Garcia Figueiredo ${ }^{2}$
}

\begin{abstract}
Pore pressure modeling has been fundamental on several applications and stages of hydrocarbon exploration, evaluation, development and production. Pore pressure estimation is generally obtained from seismic velocity data and pore pressure analysis on wells. There are many methods available for pore pressure analysis, although more recently the application of the geostatistical approach is increasing in popularity and proving to be an important method for pore pressure gradient prediction in challenging areas where pore pressure prediction is difficult using deterministic methods. In this case study on a new frontier area in the Brazilian Equatorial Margin, multivariate geostatistics allowed integration of data at different scales and spatial variations of seismic and well variables produce pore pressure gradient models. The final result is a geopressure model where one can easily extract well-conditioned pore pressure information at any location.
\end{abstract}

Keywords: geostatistical approach, different scales, pore pressure gradient models.

RESUMO. A modelagem de pressão de poros tem sido fundamental em diversas aplicações e etapas da exploração, avaliação, desenvolvimento e produção de hidrocarbonetos. Em geral, a estimativa de pressão de poros é obtida a partir da integração de dados de velocidade sísmica e análise de pressão de poros em poços. Existem diversos métodos para análise de pressão de poros, entretanto, atualmente, a aplicação da abordagem geoestatística está crescendo em popularidade e provando ser um importante método para predição de gradiente de pressão de poros em áreas de fronteiras onde a previsão de pressão de poros usando métodos determinísticos não é bem sucedida. Neste estudo de caso, localizado em uma área de nova fronteira na Margem Equatorial Brasileira, a geoestatística multivariada permitiu a integração das variáveis sísmicas e de poço em diferentes escalas e variações espaciais e a obtenção de modelos de gradiente de pressão de poros. Os resultados geraram um modelo de geopressão no qual a extração de valores de pressão de poros bem condicionados é simples em qualquer parte da área.

Palavras-chave: abordagem geostatistica, diferentes escalas, modelos de gradiente de pressão de poros.

Corresponding author: Flavia Braz Ponte

${ }^{1}$ ENAUTA - Av. Almirante Barroso, 52, sala 1301, Centro, 20031-918, Rio de Janeiro, RJ, Brazil - E-mail: flaviabponte@gmail.com

2UFF - Universidade Federal Fluminense, Programa de Pós-Graduação em Dinâmica dos Oceanos e da Terra, Av. Gen. Milton Tavares de Souza s/n, Gragoatá, Campus da Praia Vermelha, 24210-346, Niterói, RJ, Brazil -E-mails: fabioaponte3@gmail.com, adalbertosilva@id.uff.br, afigueiredo@id.uff.br 


\section{INTRODUCTION}

Anomalous pore pressure zones can cause serious issues during the drilling of exploration wells and development fields and are especially challenging in a new frontier area. Predicting pore pressure is a key tool to assist drilling engineers regarding operational safety and dimensioning of drilling and completion engineering projects, and consequently, improving well performance, reducing operational cost, and rig time (Huffman et al., 2011) as well as reducing safety operational risks. Drilling events such as kicks, blowouts, well collapse, stuck pipes and elevated torques are the most common problems resulting from pore pressure anomalies due to misestimating the pore pressure and poorly predicting its behavior. In reservoir studies, the knowledge of the pore pressure distribution allows the optimization of oil fields with a better spatial arrangement of production and injector wells, allowing greater production efficiency and oil and gas recovery. Geopressure modeling has a paramount role during the preliminary phase of exploratory studies to evaluate risk factors, including formation fluid migration and seal effectiveness (Dutta, 2002).

In this paper, a case study regarding pore pressure modeling being applied to the Brazilian Equatorial Margin is presented. The area is considered a challenging play for pore pressure prediction using commonly used methods due to the presence of a thick carbonate platform above the interval of interest. Usually, these pore pressure prediction methods use mainly data directly derived from evaluation logging tools, such as sonic, resistivity, porosity and density logs. These logs show the relationship between compaction, porosity, density, and the electrical and acoustic properties of sediments (Chopra \& Huffman, 2006). Taking into account the thick carbonate package overlaid and knowing that carbonates suppress the sensitivity of the shale velocity to pore pressure (Huffman et al., 2011), a 3D pore pressure volume using multivariate geostatistics was adopted as a solution to predict the pore pressure in this area. Multivariate geostatistics techniques are promising tools to achieve high-quality pore pressure distribution and reservoir characterization maps integrating well and seismic data. Therefore, the method can predict more accurate pressure values and ensure significant risks and costs.

In this study, we used hard data from five exploratory wells, identified as well $A, B, C, D$ and $E$, which were used as a predictive variable in geostatistical interpolation, and velocity data derived from seventeen PSDM (Pre-Stack Depth Migration) seismic lines as the secondary geostatistical modelling variable. The hard data incorporates parameters as well as geological and geophysical logging data.

\section{THEORY}

\section{Pressure Prediction}

Sedimentary basins are subject to anomalous pore pressure originated by subcompaction mechanisms, fluid expansion, hydrocarbon generation and tectonism (Osborne and Swarbrick, 1997). The normal pore pressure depends on the environment and is equal to the pressure exerted by the hydrostatic column of the formation fluid. The determination of the drilling fluid density is a key factor responsible for the pressure exerted from borehole space against the formation wall as a means for controlling and holding in place the formation fluids and ensuring the best well mechanical properties.

The main steps and concepts involved in the estimation of formation pressure in sedimentary basins are briefly described below:

(1) Calculating the Hydrostatic Pressure

The pressure produced by a column of fluid as a function of density and vertical height. It is expressed as:

$$
P_{h}=\rho . g . h
$$

where: $P_{h}$, hydrostatic pressure; $\rho$, fluid density; $g$, gravitational constant; and $h$, height of the fluid column. 


\section{(2) Calculating Overburden}

Overburden is given by the sum of all pressures exerted by all the overlapping layers, which is total vertical stress, assumed to be the given combined weight of the rock matrix and the fluids in the pore space overlying the interval of interest (Sayers et al., 2006). At a given depth it is calculated by the following integral:

$$
S=\int_{z_{0}}^{z} \rho_{b} \cdot g \cdot d z
$$

Where:

$S$, overburden; $\rho_{b}$, formation density; $g$, gravitational constant; $z$, depth of investigation; and $z$, initial depth.

The overburden gradient is determined by the relation between overburden and depth as in the following expression:

$$
G_{O V}=S / Z
$$

Where: $G_{o v}$, overburden gradient; $S$, overburden tension; and $Z$, depth in meters.

\section{(3) Calculating Pore Pressure}

The pore pressure gradient is defined by the relation between pore pressure and depth, given by the following expression:

$$
G_{P}=P_{P} /(0.1704 . Z)
$$

Where: $G_{P}$, pore pressure gradient in $\mid \mathrm{b} . \mathrm{gal}^{-1} ; P_{p}$, pore pressure in psi; and $Z$, vertical depth in meters.

There are many techniques used for pore pressure predictions or estimates. Commonly used methods to estimate the pore pressures (e.g. Eaton's method, Bowers' method and Miller's method) are based on shale properties and consider the compaction disequilibrium as the primary mechanism of overpressure generation (Zhang, 2011).

In the area of this case study, as previously mentioned, the geological constraints and the relative scantiness of data (very common when one deals with an exploratory frontier area) do not allow for the proper evaluation and modeling of pore pressure by strictly deterministic or conventional methods. Of course these methods have their applicability as indicators in the modeling process and assist in the development of models based on multivariate geostatistics techniques, such as the LVM (Locally Varying Mean) kriging as here applied to the prediction of pore pressure.

\section{METHODOLOGY}

As previously mentioned, this study adopts a pore pressure modeling strategy based on multivariate geostatistics where the primary variable is composed of hard data obtained directly in the well and the secondary variable is given by the seismic velocity data that support the three-dimensional space population of the area of interest. The integration of these data results in a more coherent and robust pore pressure models.

The LVM technique can be applied when the secondary variable (e.g. seismic velocity) is comprehensive in volume or area and is well sampled in the entire region of interest. LVM is a variation of the simple kriging technique (which "requires that the mean of the variable over the field being estimated be constant and know" as in Journel, 1989), where the mean of the variable is known and only locally valid, as it varies from place to place over the area of study.

In this study the pressure model was built according to the following steps:

- Well logging data as a primary variable - The first step was the data collecting and determination of the 1D pore pressure gradient for the five wells. The recorded pore pressure data from wells was used as predicted variables. This dataset is a compilation of prior direct (hard data) information from: formation tests, pore pressure estimations from drilling parameters and leak-off tests (LOT);

- Seismic data as a second variable - The second step 
comprises the interpretation of seismic data and the definition of a range of interest required to evaluate the abnormal pressure zone, and is executed by the interpreter. For better results and usability, a 3D pore pressure model is necessary, so the third step is generating a three-dimensional velocity cube from $2 \mathrm{D}$ seismic lines. This velocity cube was estimated with the geostatistical method of simple kriging, which involves a stationary function with known mean as previously stated. The estimator is a linear function of the data with weights calculated according to the specifications of unbiasedness and minimum variance. In selecting the weights of the linear estimator, kriging accounts for the relative distance of measurements from each other and from the location where an estimate is sought. The area of influence of each measurement is essentially considered (Kitanidis, 1999);

- The fourth and last step comprises the estimation of a geostatistical 3D pore pressure model from the 3D velocity cube obtained before. The generation of multivariate geostatistical models consists of four main steps:

1 - Data preparation is a step which should be planned and executed by the interpreter because is mandatory that the used seismic attribute has a consistent correlation with the subject geological property in the modeled interval;

2 - Exploratory Analysis: The primary (pore pressure measured in wells) and secondary data (seismic velocity) were analyzed by frequency histograms and cross-plots to evaluate the correlation between them and the data distribution;

3 - Study of the spatial continuity through structural functions in several directions;

4 - Pore pressure estimation: applying the kriging algorithms to generate an image with minimum variance.

In this study the LVM kriging was applied because the variables do have a local variable mean as distinctive behavior. As pointed out before, this is an important tool for quantifying the uncertainties of a given oil reservoir as a result of a numerical model that allows representing the reservoir attribute as a continuous function in this particular portion of the $3 \mathrm{D}$ space. The local estimate in LVM is attained by mapping the residuals calculated by solving the linear kriging system in each grid location and adding the mean given by the secondary variable.

For example, considering primary information sampled in $n$ number of $u_{\alpha}$ locals:

$$
\left\{z\left(u_{\alpha}\right), \quad \alpha=1, \ldots, n\right\}
$$

In LVM, secondary information is present in each $u$ local where it is necessary to have an estimate. Then, the stationary average of the simple kriging system in u position can be replaced by non-stationary local averages given by the secondary variable $m^{*}$ :

$$
Z_{\text {lvm }}^{*}(u)-m^{*}(u)=\sum_{\alpha=1}^{n(u)} \lambda_{\alpha} \cdot\left[Z\left(u_{\alpha}\right)-m^{*}\left(u_{\alpha}\right)\right]
$$

The estimated value of the $Z$ variable in $u$ position follows the stages below:

(1) the average of the primary variable is determined as a function of the secondary variable $y$ :

$$
m^{*}(u)=f(y(u))
$$

(2) the kriging weights are determined by solving the system:

$$
\begin{aligned}
& \sum_{\beta=1}^{n(u)} \lambda_{\beta} \cdot C_{R}\left(u_{\alpha}-u_{\beta}\right)=C_{R}\left(u_{\alpha}-u\right), \\
& \alpha=1, \ldots, n(u)
\end{aligned}
$$

where, $C_{R}(h)$ is the covariance function of the random residual variable;

(1) the experimental residues are determined:

$$
r\left(u_{\alpha}\right)=z\left(u_{\alpha}\right)-m^{*}\left(u_{\alpha}\right)
$$

(2) the variogram of the residues is calculated;

(3) the variogram of the residues is modeled; 
(4) the residues are estimated using kriging;

(5) the result is obtained by adding the average of the secondary variable to the residue estimates.

\section{RESULTS AND ANALYSIS}

1D pore pressure models were defined from drilling parameters, drilling mud weight, leak-off test (LOT) and formation tests (RFT), provided by ANP, the Brazilian Petroleum Agency. The results of the 1D pore pressure gradient, in each well, are shown graphically in Figures 1, 2, 3,4 and 5 .

All wells were drilled in the shallow water portion of the basin where a thick carbonate platform overlays the interest interval here studied. Pore pressure anomalies have been identified in three wells (A, C and D) out of the five analyzed wells. Regions with possible abnormal pressure are highlighted in pale green shades, called APZ (Abnormal Pressure Zones). Those are the prime interval of interest for this study.

The figures are separated into two panels. On the left, the variables most closely linked to the petrophysical properties of the formation rocks: from left to right, the first track is interpreted lithology, the second track records measured compressional sonic velocity (Vp), the third track is measured density and fourth is calculated acoustic impedance. On the right panel, a depth versus pressure plot, several important curves are depicted: the pore pressure gradient recorded on the well drilling report, the pore pressure gradient equivalent to the mud weight, the overburden gradient and the normal pore pressure gradient, as well as formation test data and leak-off tests when available.

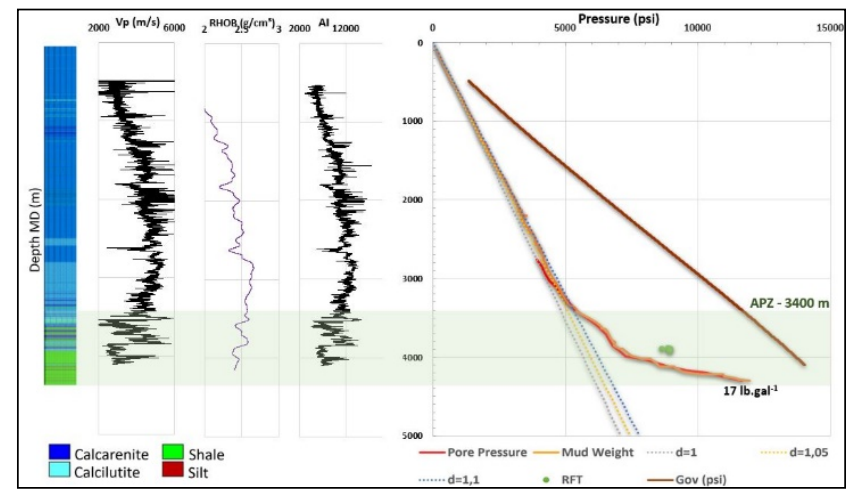

Figure 1 - Original curves and pressure lines of well A.

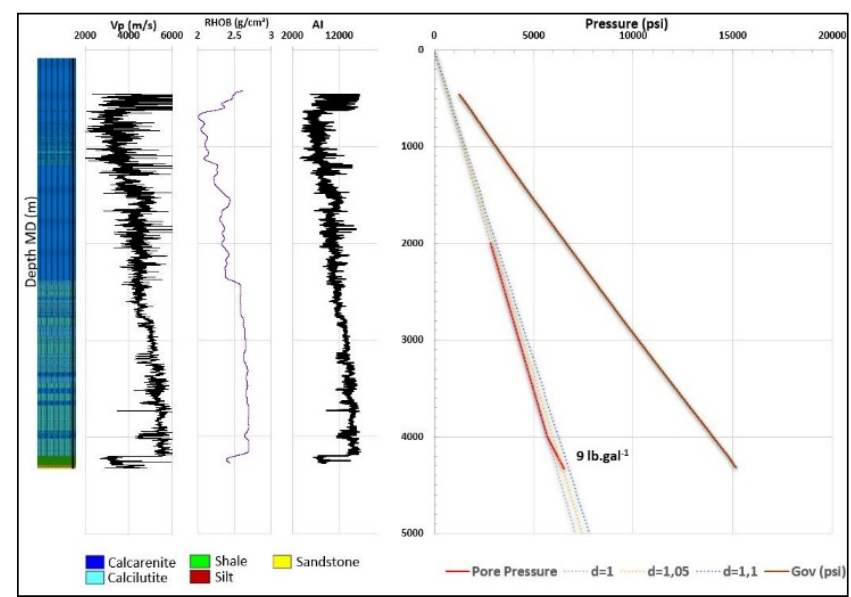

Figure 2 - Original curves and pressure lines of well B.

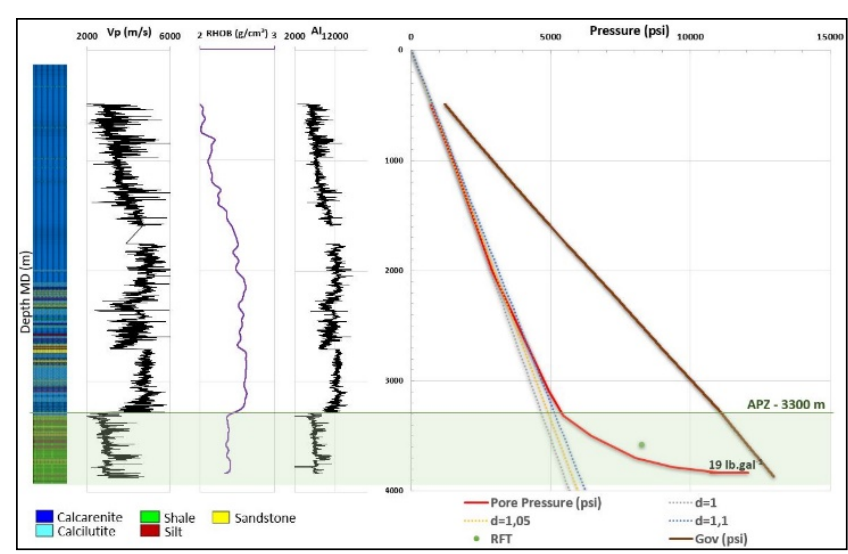

Figure 3 - Original curves and pressure lines of well C. 


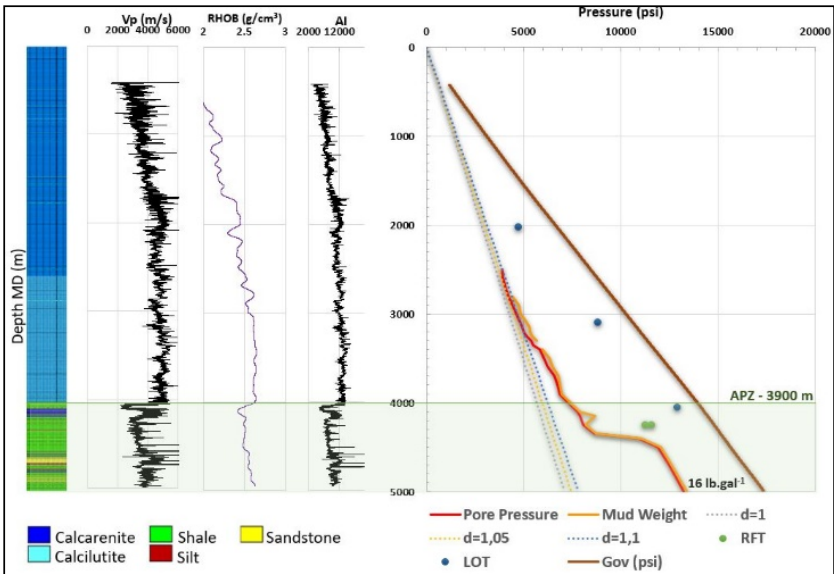

Figure 4 - Original curves and pressure lines of well D.

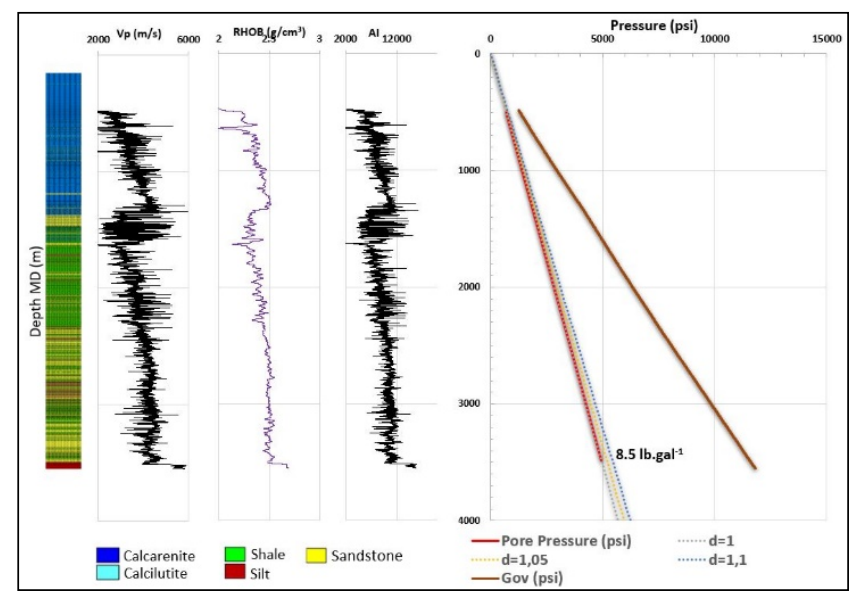

Figure 5 - Original curves and pressure lines of well $\mathrm{E}$.

As depicted in Figures 1 and 3 , in the wells A and C, respectively, the equivalent mud weight reaches a maximum of $17 \mathrm{lb} . g a l^{-1}(\mathrm{ppg})$ in well $A$ and $19 \mathrm{lb} . g a l^{-1}(\mathrm{ppg})$ in well C. Similarly, the well D in Figure 4 shows the same behavior and makes with well $A$ and $C$ a distinct group with registered APZ. The two remaining wells, B and E (Figs. 2 and 5, respectively) do not develop a conspicuous APZ (well B) or does not have any indication of abnormal pressures (well E).

\section{Pressure analysis from 2D seismic data}

Due to the sparse well distribution, integrating multiple variables to control the modeling process becomes essentially critical (Han et al., 2018) because a simple interpolation solution cannot provide a usable model at the needed scale. Thus, to increase the accuracy of the stochastic model on places without well information, the interval velocity data extracted from the seismic data was integrated as an additional conditioning data (a second variable). Stochastic methods, such as kriging allow us to incorporate a broad range of information from various sources. These methods are important not only for its range of plausible outcomes but for its ability to integrate additional "soff" data (e.g., seismic). It improves the reliability of the realizations not close to the control points and only secondary parameters are available (Chambers et al., 2000).

The velocity data analysis in 2D sections demonstrate a smooth behavior and is partially follows the well velocity records. The reason for the difference between velocity data may be related to the types of frequency used in well data acquisition (high frequencies) and ground seismic (low frequencies). However, such differences do not affect the fact that variations in seismic velocity are intrinsically related to variations in pore pressure and that their spatial distribution certainly contributes to improving the model strictly based on the sparse hard data available in the wells.

Currently, 3D seismic data are used to increase the model spatial distribution and resolution, being useful to improve reservoir characterization ( $\mathrm{Xu}$ et al., 1992). Due to this, an interval velocity cube from 2D seismic data was created by simple kriging interpolation (Fig. 6), as previously described. This densely sampled cube allows us to populate the pore pressure 3D model and to generate useful information on an appropriate working scale. 


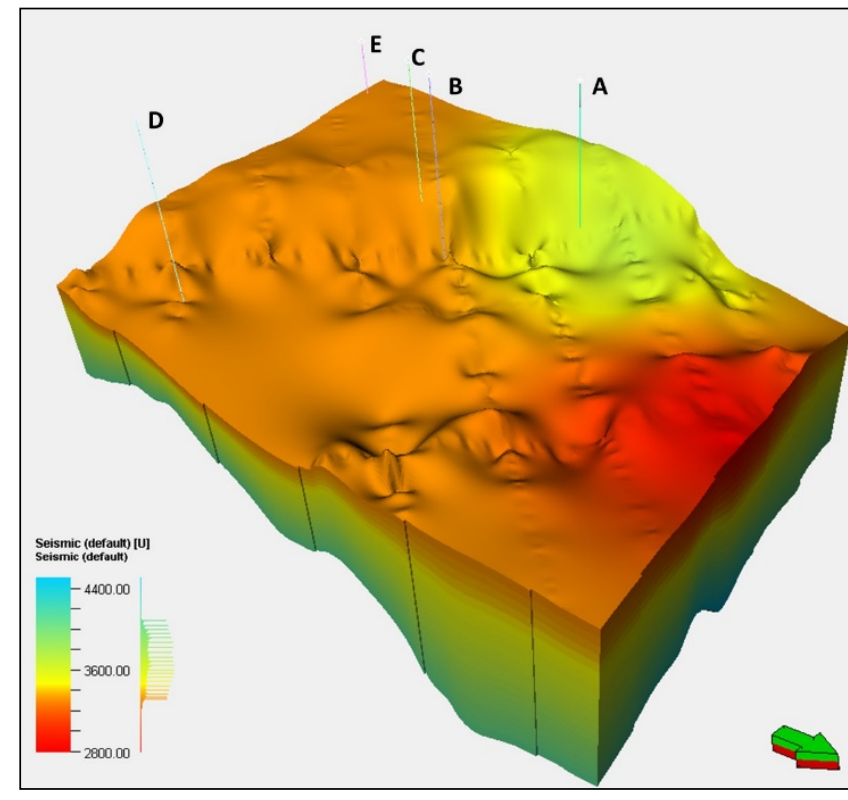

Figure 6 - Velocity Cube generated from 2D seismic data with well positions.

Histogram analysis of velocity data from seismic cubes and velocity data from wells shows a similarity in distribution type, defined as close to a Gaussian distribution, with global averages of $3676,7 \mathrm{~m} . \mathrm{s}^{-1}$ and $4401,64 \mathrm{~m} . \mathrm{s}^{-1}$, respectively, as can be seen in Figure 7.

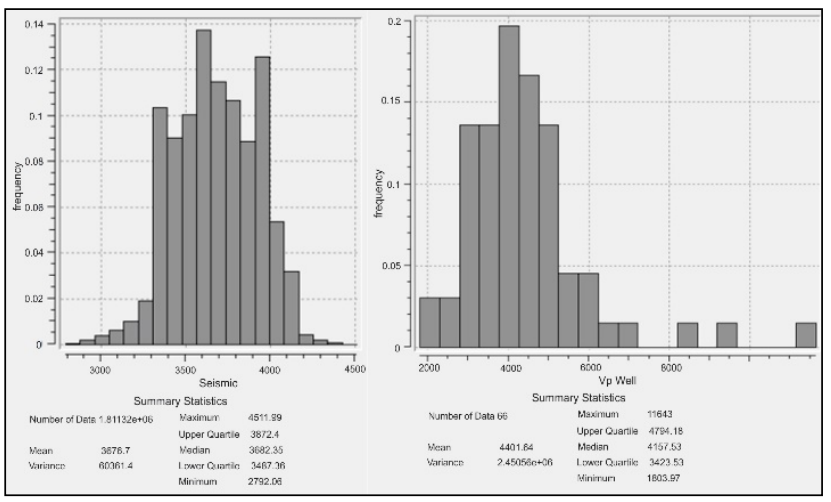

Figure 7 - Histogram of interval velocity from the estimated seismic cube and velocities from wells. Sonic velocity data were not edited and some spurious values (above $\sim 7,000$ $\mathrm{m} / \mathrm{s}$ ) should be disregarded.

\section{Multivariate Geostatistical approach}

A major advantage of using kriging instead of other interpolation algorithms is the capacity to use more than one variable simultaneously to predict the value at an unsampled location (Yarus \& Chambers, 2006). This procedure is called multivariate geostatistics and allows data integration by merging different scales of acquisition to produce high-quality pore pressure models based on seismic and well data.

The kriging procedure requires that the spatial correlation and variability function of the variable are known for different distances and azimuths. This condition is met using an experimental variogram directly derived from the raw data and numerically fitted to a model that describes the spatial variance of the variable in any location of the studied field. The experimental variogram of the 3D seismic velocity cube for azimuthal directions $0^{\circ}$ and $90^{\circ}$ (Fig. 8) fit to a Gaussian variogram model in both NS and EW directions with a range of $1,000 \mathrm{~m}$ and $700 \mathrm{~m}$, a nugget effect of 10,000 and 100 and sill with 150,000 and 80,000 , respectively. The velocity exhibits a distinct zone anisotropic behavior with different sills indicating greater continuity at $90^{\circ}$ nearly parallel to the EW fault trend in the area.

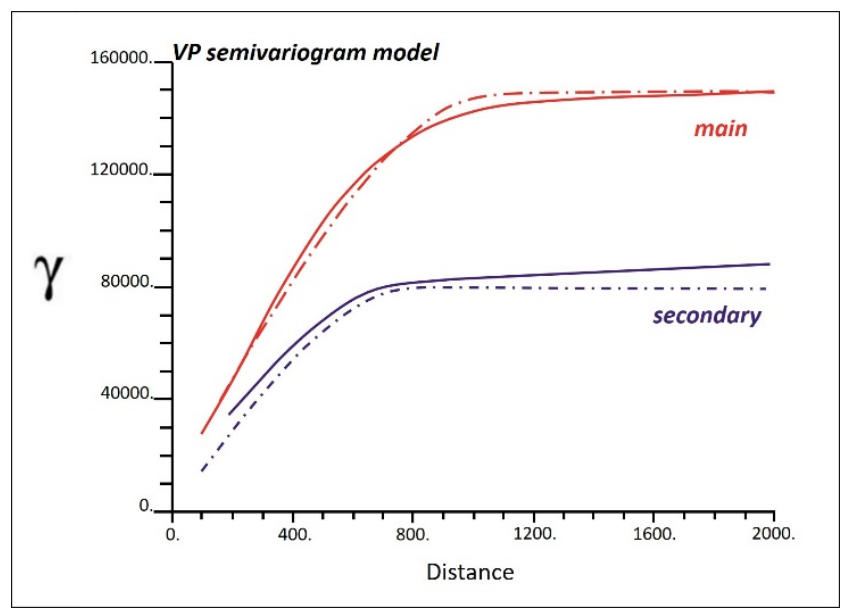

Figure 8 - Horizontal semivariograms at the main and secondary directions. The dash-dotted lines correspond to the fitted variogram model and the continuous lines represent the experimental variogram (obtained from data).

The modelled velocity variogram was used to generate the pore pressure cube by LVM interpolation as depicted in Figure 9.

The figures above $10 \mathrm{lb} . g a l^{-1}(\mathrm{ppg})$ indicate the highpressure anomalies as portrayed by the warm colors on the platform region are in close match to the recorded data in the 
wells used in this study, where there are known intervals with pore pressure anomalies. This modeled interval is enclosed in a thick Upper Cretaceous clay section and the complex tectonic environment (distensive/compressive system) of this equatorial margin exploration area, as observed in the SW$\mathrm{NE}$ section in the Figure 9, can be the triggering mechanism for these pore pressure anomalies.

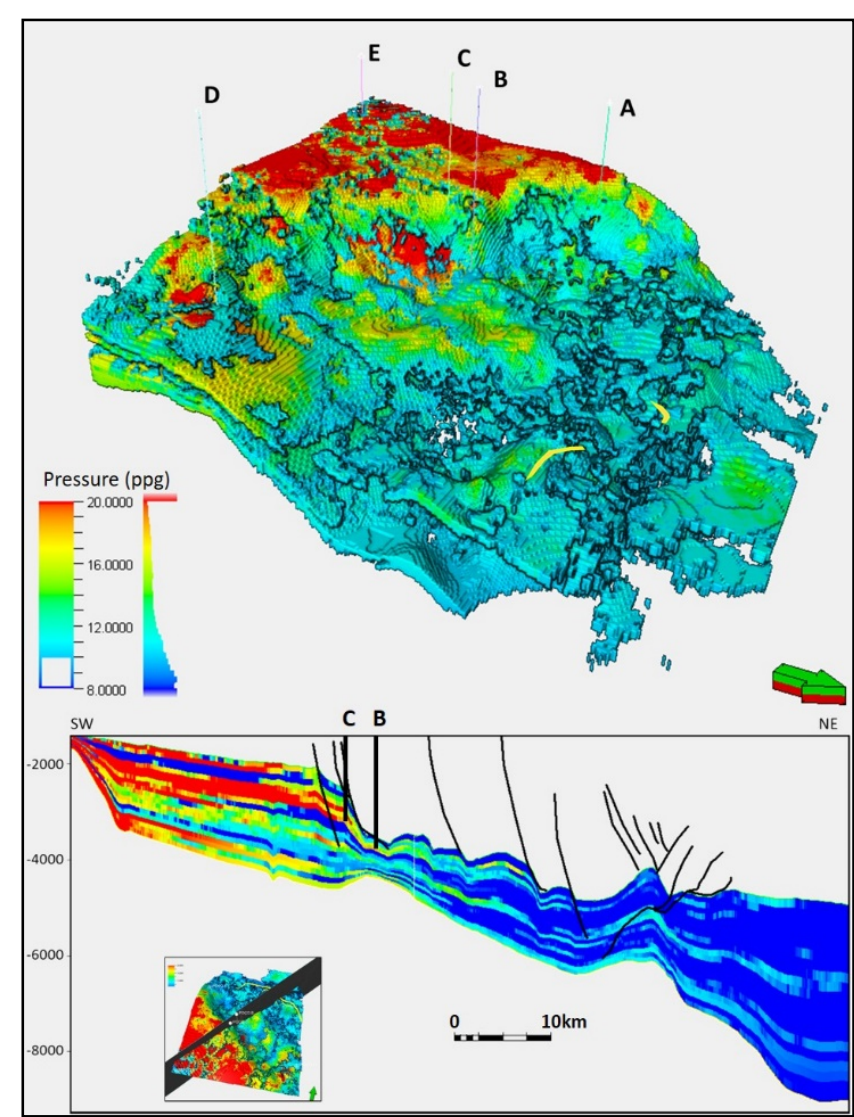

Figure 9 - Pore pressure estimated using LVM techniques.

As a validation tool, the distribution analysis in Figure 10 shows the correspondence between hard data from wells (in red), and modeled pore pressure based on the upscaled seismic (in green) and from LVM interpolation (in blue).

As shown in Table 1, there is a relatively close match between hard data and the calculated pore pressure distribution thus endorsing the application of the technique used in this study.

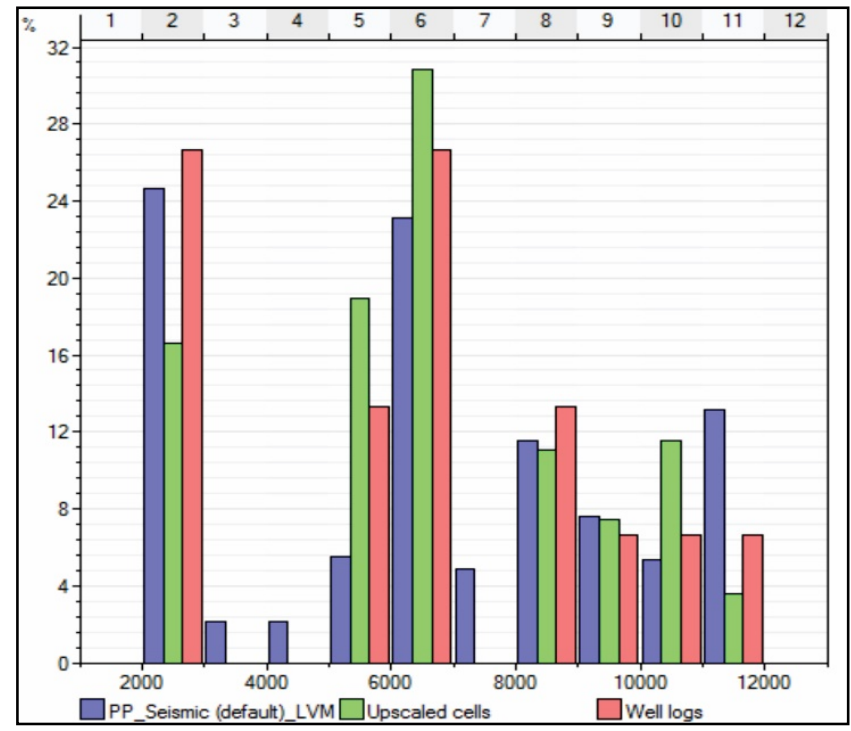

Figure 10 - Frequency histogram of pore pressure distribution from the 3D model (blue); seismic (green) and wells (red).

Table 1 - Pore pressure mean and standard deviation (in psi) in the wells, upscaled seismic model and LVM 3D model.

\begin{tabular}{cccc}
\hline & Well & Seismic & LVM \\
\hline Mean & $6,283.65$ & $6,643.07$ & $6,670.86$ \\
SD & $3,047.03$ & $2,695.90$ & $3,245.62$ \\
\hline
\end{tabular}

\section{CONCLUSIONS}

The use of multivariate geostatistics techniques to model pore pressure in exploration settings is a promising practice because it can deliver fast, robust and easily implemented solutions to derive high-quality maps and volumes with good accuracy far better than others based only on data acquired in wells. This is especially true in exploration frontier scenarios where hard data from wells are scarce.

The exploratory data analysis indicates a good correlation between the predictive (hard data) and secondary (seismic velocity) variables and gives grounds for the LVM estimation. The resulting pressure cube covers the entire interest interval and shows a distinctive high-pressure cluster in the shallow platform region. The high-pressure sections 
are associated with clay intervals as shown in the wells used for this study.

The clear anisotropic velocity behavior and its correlation with the pore pressure distribution along the main EW fault direction corroborate that this anomalous pressure field is related to the complex tectonic setting in this portion of the continental margin.

The results here shown incorporate important information and a simple workflow that can be easily incorporated to minimize operational risks and enhance well location and drilling projects in these hazardous but promising areas.

\section{ACKNOWLEDGEMENTS}

The authors would like to thank Enauta and WesternGeco for supplying seismic lines and velocity, ANP, UFF and all who contributed to the accomplishment and publication of this paper.

\section{REFERENCES}

CHAMBERS RL, YARUS JM \& HIRD KB. 2000. Petroleum Geostatistics for Nongeostatisticians. Part 2. Geophysics: The Leading Edge of Exploration, 19(6): 592-599.

CHOPRA S \& HUFFMAN AR. 2006. Velocity Determination for Pore-Pressure Prediction. The Leading Edge, 25(12): 1441-1568.

DUTTA NC. 2002. Geopressure Prediction using Seismic Data: Current Status and the Road Ahead: Geophysics, 67(6): 2012-2041.

HAN F, ZHANG H, GUO Q, WEI K \& SHANG Z. 2018. An
Integrated Method for Seismic Velocity Modeling Based on Collocated Cokriging. Sinopec Geophysical Research Institute - Journal of Geophysics and Engineering, APR, 1389-1398.

HUFFMAN AR, MEYER J, GRUENWALD R, BUITRAGO J, SUAREZ J, DIAZ C, MUNOZ JM \& DESSAY J. 2011. Recent Advances in Pore Pressure Prediction in Complex Geologic Environments. In: SPE Middle East Oil and Gas Show Conference. Manama, Bahrain. SPE-142211-MS.

JOURNEL AG. 1989. Fundamentals of Geostatistics in Five Lessons. Short Course in Geology, vol. 8, AGU, Washington DC. 40 pp.

KITANIDIS PK. 1999. Introduction to Geostatistics: Applications in Hydrogeology. Cambridge University Press, Cambridge, UK. 1999. 249 pp.

OSBORNE MJ \& SWARBRICK RE. 1997. Mechanisms for Generating Overpressure in Sedimentary Basins: A Reevaluation: AAPG Bulletin, 81: 1023-1041.

SAYERS CM, DEN BOER LD, NAGY ZR \& HOOYMAN PJ. 2006. Well-constrained Seismic Estimation of Pore Pressure with Uncertainty. The Leading Edge, 25(12): 1524-1526.

XU W, TRAN TT, SRIVASTAVA RM \& JOURNEL AG. 1992. Integrating Seismic Data in Reservoir Modelling: The Collocated Cokriging Alternative. In: SPE Annual Technical Conference and Exhibition. Washington, DC. SPE 24742.

YARUS JM \& CHAMBERS RL. 2006. Practical Geostatistics - An Armchair Overview for Petroleum Reservoir Engineers. Journal of Petroleum Technology, SPE 103357, 78-87.

ZHANG JJ. 2011. Pore Pressure Prediction from Well Logs: Methods, Modifications, and New Approaches. EarthScience Reviews, 108(1): 50-63. 